\title{
Effects of Continuous Intravenous Infusion of Dexmedetomidine on the Duration of Spinal Anesthesia: A Prospective, Double-Blind, Randomized, Controlled Trial
}

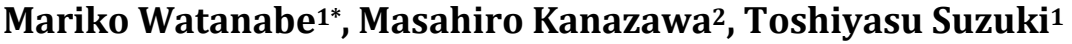 \\ ${ }^{1}$ Department of Anesthesiology, Tokai University School of Medicine, Isehara, Japan \\ ${ }^{2}$ Division of Anesthesia, Subaru Health Insurance Society Ota Memorial Hospital, Ota, Japan \\ Email: ^9j236559@is.icc.u-tokai.ac.jp
}

How to cite this paper: Watanabe, M., Kanazawa, M. and Suzuki, T. (2018) Effects of Continuous Intravenous Infusion of Dexmedetomidine on the Duration of Spinal Anesthesia: A Prospective, Double-Blind, Randomized, Controlled Trial. Open Journal of Anesthesiology, 8, 55-65.

https://doi.org/10.4236/ojanes.2018.83006

Received: February 8, 2018

Accepted: March 6, 2018

Published: March 9, 2018

Copyright $\odot 2018$ by authors and Scientific Research Publishing Inc. This work is licensed under the Creative Commons Attribution International License (CC BY 4.0).

http://creativecommons.org/licenses/by/4.0/

cC) (7) Open Access

\begin{abstract}
Background: Spinal anesthesia with sedation is a common anesthetic technique in infraumbilical surgeries. Dexmedetomidine has been widely used as a sedative during spinal anesthesia, and is recognized as an adjuvant that prolongs the duration of spinal anesthesia. We compared the effects of a continuous intravenous infusion of dexmedetomidine to provide intraoperative sedation on the duration of sensory and motor blockade induced by spinal anesthesia, with those of midazolam. Methods: A double-blind randomized controlled trial was performed on 40 patients, aged between 20 and 75 years, who requested intraoperative sedation, and were classified as American Society of Anesthesiologists (ASA) physical status I-II, and underwent elective surgeries under spinal anesthesia. After spinal anesthesia with $13 \mathrm{mg}(2.6 \mathrm{ml})$ of $0.5 \%$ hyperbaric bupivacaine, patients were randomized to receive intravenous dexmedetomidine $3 \mu \mathrm{g} / \mathrm{kg} / \mathrm{h}$ for 10 mins followed by an infusion of 0.5 $\mu \mathrm{g} / \mathrm{kg} / \mathrm{h}$ (Group D), or intravenous midazolam $0.15 \mathrm{mg} / \mathrm{kg} / \mathrm{h}$ for $10 \mathrm{mins}$ followed by an infusion of $0.025 \mathrm{mg} / \mathrm{kg} / \mathrm{h}$ (Group M). Sedation was titrated to Observer's Assessment of Alertness/Sedation (OAA/S) score of 3. Sensory and motor blockade was evaluated using the pinprick test and modified Bromage scale, respectively. Results: The time taken to achieve OAA/S score 3 was similar in the two groups. The maximal level of sensory blockade was $5.3 \pm 1.3$ min in group $\mathrm{D}$ and $4.1 \pm 1.5$ in group $\mathrm{M}(P=0.03)$. No significant differences were observed in the time taken to achieve the maximal level or the two-segment regression time of sensory blockade between the two groups. The time to sensory regression to the L2 level was significantly longer in group D than in group M $(234.6 \pm 78.1$ mins versus $172.4 \pm 41.5$ mins, respec-
\end{abstract}


tively, $P=0.008)$. The time to motor regression to modified Bromage score 1 was significantly longer in group $D$ than in group $M(232.2 \pm 79.3$ versus $176.5 \pm 48.8$, respectively, $P=0.02$ ). Conclusion: Continuous intravenous dexmedetomidine to provide sedation during spinal anesthesia significantly prolongs the duration of sensory and motor blockade induced by spinal anesthesia over that with midazolam.

\section{Keywords}

Dexmedetomidine, Spinal Anesthesia, Sedation

\section{Introduction}

Spinal anesthesia is a common anesthetic technique in infraumbilical surgeries, and sedation is often performed during spinal anesthesia [1]. Midazolam, which is a benzodiazepine sedative, has been used intravenously to provide sedation during spinal anesthesia, and dexmedetomidine is now being more widely used [2]. Dexmedetomidine is a highly selective $\alpha 2$-adrenergic agonist that induces higher quality sedation than other $\gamma$-aminobutyric acid receptor (GABA) agonists (propofol and benzodiazepines) without severe respiratory depression [3]. Furthermore, dexmedetomidine exerts its analgesic effects via the activation of $a 2$-adrenergic receptors in the spinal cord, and has been employed as an intrathecal adjuvant to local anesthetic [4]. However, intravenous dexmedetomidine also significantly prolonged the duration of sensory blockade induced by bupivacaine spinal anesthesia [5]. This finding indicates that not only the intrathecal administration, but also the systemic administration of dexmedetomidine alters the duration of spinal anesthesia from that with intravenous midazolam. Dexmedetomidine as a sedative agent during regional anesthesia is administered via continuous intravenous infusion following an initial loading dose. However, few studies have investigated the effects of dexmedetomidine as a sedative on the duration of blockade induced by bupivacaine spinal anesthesia. Therefore, in this prospective double-blind randomized controlled trial, we compared the effects of the continuous intravenous infusion of dexmedetomidine to provide intraoperative sedation on the duration of sensory and motor blockade induced by bupivacaine spinal anesthesia, with those of midazolam.

\section{Patients and Methods}

This study protocol, performed between October 2013 and March 2017, was approved by the Institutional Review Board for Clinical Research in Tokai University hospital (13R-165), and written informed consent was obtained from each patient. Forty patients who requested sedation during surgery, aged between 20 and 75 years, classified as American Society of Anesthesiologists (ASA) physical status I or II, and undergoing elective lower abdominal or lower limb surgery 
under spinal anesthesia were enrolled.

Patients were excluded for any of the following reasons: no request for sedation during surgery, contraindications to spinal anesthesia, pregnancy, obese patients (body mass index > 30), patients with cardiovascular (including arrhythmia), respiratory, hepatic, renal, neurological, or psychological diseases, the use of any analgesics or sedative drugs, and a history of alcohol abuse. No patient received premedication. An intravenous line was inserted at a hospital ward, and the administration of extracellular fluid was initiated. On arriving at the operating room, standard hemodynamic monitoring was performed, including electrocardiography, pulse oximetry, and non-invasive blood pressure measurements (BSM-6501, 1763; Nihon Kohden Co., Ltd., Tokyo, Japan). Patients were placed in the lateral position and dural puncture was performed at the L3-L4 interspace with a 25-G Quincke needle. After ensuring the free flow of cerebrospinal fluid, $13 \mathrm{mg}(2.6 \mathrm{~mL})$ of $0.5 \%$ hyperbaric bupivacaine was injected intrathecally. Patients were then turned to the supine position and received oxygen 4 $1 /$ min via a facemask throughout the procedure. Patients were randomly and equally divided into two groups: group D (dexmedetomidine group) and group $\mathrm{M}$ (midazolam group), using random numbers generated by a computer. Dexmedetomidine and midazolam were diluted with normal saline to a final volume of $50 \mathrm{~mL}(4 \mu \mathrm{g} / \mathrm{mL}$ and $0.2 \mathrm{mg} / \mathrm{ml}$, respectively) in $50-\mathrm{mL}$ syringes. These syringes were masked with black tape by an anesthesiologist who was not involved in this study. Five minutes after dural puncture, group D patients $(n=20)$ received a loading dose of $3 \mu \mathrm{g} / \mathrm{kg} / \mathrm{h}$ of dexmedetomidine $(200 \mu \mathrm{g} / 50 \mathrm{ml})$ for 10 minutes (equal to $0.5 \mu \mathrm{g} / \mathrm{kg}$ over $10 \mathrm{mins}$ ) followed by a maintenance dose of 0.5 $\mu \mathrm{g} / \mathrm{kg} / \mathrm{h}$ intravenously. Group M patients $(\mathrm{n}=20)$ received a loading dose of 0.15 $\mathrm{mg} / \mathrm{kg} / \mathrm{h}$ of midazolam $(10 \mathrm{mg} / 50 \mathrm{ml}$ ) for 10 minutes (equal to $0.025 \mathrm{mg} / \mathrm{kg}$ over 10 mins) followed by a maintenance dose of $0.025 \mathrm{mg} / \mathrm{kg} / \mathrm{h}$ intravenously. The Observer's Assessment of Alertness/Sedation (OAA/S) scale was used to evaluate the sedation state [6] (Table 1). The score was reevaluated appropriately throughout the procedure. The infusion rate was decreased to half or increased 2 -fold in order to maintain OAA/S score 3 at the maintenance dose. Levels of sedation were assessed at 5-min intervals until OAA/S score 3 was achieved and when the sensory blockade level was being assessed. The sensory blockade level was assessed by the pinprick test at 2-min intervals until the maximal level of sensory blockade was achieved, and then at 15-min intervals until regression to the L2 level. Motor blockade was assessed by the modified Bromage Scale [7]: modified Bromage 0 , able to move the hip, knee, and ankle; modified Bromage 1, unable to move the hip, but able to move the knee and ankle; modified Bromage 2, unable to move the hip or knee, but able to move the ankle; and modified Bromage 3, unable to move the hip, knee, or ankle, and was checked at 15-min intervals (immediately after the sensory blockade assessment) until regression to modified Bromage score 1.

Patients with hypotension (systolic pressure $<80 \mathrm{mmHg}$ ) were treated with fluid replacement and intravenous ephedrine at bolus doses of $4 \mathrm{mg}$, while those 
Table 1. Observer's assessment of alertness/sedation scale (OAA/S).

\begin{tabular}{ccccc}
\hline Subscore & Responsiveness & Speech & $\begin{array}{c}\text { Facial } \\
\text { expression }\end{array}$ & Eyes \\
\hline 5 & $\begin{array}{c}\text { Responds readily to name } \\
\text { spoken in normal tone } \\
\text { Lethargic response to name } \\
\text { spoken in normal tone }\end{array}$ & $\begin{array}{c}\text { Mild slowing or } \\
\text { thickening }\end{array}$ & Mild relaxation & Clear \\
& $\begin{array}{c}\text { Glazed mild } \\
\text { ptosis }\end{array}$ \\
3 & $\begin{array}{c}\text { Responds only after name } \\
\text { spoken loudly or repeatedly }\end{array}$ & Slurring or slowing & $\begin{array}{c}\text { Marked } \\
\text { relaxation }\end{array}$ & $\begin{array}{c}\text { Glazed marked } \\
\text { ptosis }\end{array}$ \\
& $\begin{array}{c}\text { Responds after mild prodding } \\
\text { or shacking }\end{array}$ & $\begin{array}{c}\text { Few recognizable } \\
\text { words }\end{array}$ & & \\
& Dose not respond to mild & & & \\
prodding or shaking & & & \\
\hline
\end{tabular}

with bradycardia (heart rate $<50$ beat $/ \mathrm{min}$ ) were treated with intravenous atropine at $0.01 \mathrm{mg} / \mathrm{kg}$.

\section{Statistical Analysis}

In order to detect a 20-min difference in the mean duration of sensory blockade with a standard deviation of $20 \min (\alpha=0.05, \beta=0.02)$, a minimum sample size of 17 in each group was estimated using $\mathrm{G}^{*}$ power software (version 3.1.7) based on previous findings [8]. Data were analyzed statistically using GraphPad Prism 5.0 software. All data were presented as the mean and standard deviation (SD) or the number of patients with percentages. The unpaired $t$-test or Mann-Whitney $\mathrm{U}$ test was used appropriately for intergroup comparisons. Probability values of $P<0.05$ were considered to be significant.

\section{Results}

Spinal anesthesia failed in two patients in group D and one in group M. Furthermore, one patient in group $M$ was changed to general anesthesia for surgical reasons. Therefore, two patients in each group did not complete the study. No significant differences were observed in age, weight, height, the duration of surgery, duration of anesthesia, or type of surgery between the two groups (Table 2). Table 3 shows the OAA/S scale scores and characteristics of sensory and motor blockade. The time taken to achieve OAA/S score 3 was similar in the two groups. The maximum upper levels of sensory blockade in groups $\mathrm{D}$ and $\mathrm{M}$ were $5.3 \pm 1.3$ and $4.1 \pm 1.5 \mathrm{~min}$, respectively, and it was significantly lower in group $\mathrm{D}$ than in group $\mathrm{M}(P=0.03)$. However, no significant differences were noted in the time taken to achieve the maximum upper levels of sensory blockade between the two groups. The times for the two-segment regression of sensory blockade were similar in the two groups. The times for regression to the L2 level of sensory blockade in groups $\mathrm{D}$ and $\mathrm{M}$ were $234.6 \pm 78.1 \mathrm{~min}$ and $172.4 \pm 41.5$ min, respectively, and it was significantly longer in group $\mathrm{D}$ than in group $\mathrm{M}(P=$ 0.008). No significant difference was observed in the time taken to achieve the 
Table 2. Demographic data and intraoperative characteristics.

\begin{tabular}{cccc}
\hline & Group D $(\mathrm{n}=18)$ & Group M (n=18) & $P$ value \\
\hline Age (years) & $56.5 \pm 22.3$ & $58.13 \pm 13.9$ & 0.81 \\
Weight $(\mathrm{kg})$ & $62.4 \pm 5.8$ & $64.9 \pm 9.3$ & 0.36 \\
Height $(\mathrm{cm})$ & $166.5 \pm 6.3$ & $165.6 \pm 7.8$ & 0.74 \\
Duration of surgery (min) & $53.8 \pm 24.0$ & $54.6 \pm 32.6$ & 0.94 \\
Duration of anesthesia (min) & $79.3 \pm 22.8$ & $76.3 \pm 30.5$ & 0.76 \\
Type of surgery & & & 0.53 \\
Lower abdominal & $8(44 \%)$ & $6(33 \%)$ & \\
Lower limb & $10(56 \%)$ & $12(67 \%)$ & \\
\hline
\end{tabular}

Values are expressed as the mean $\pm \mathrm{SD}$ or number of patients with percentages.

Table 3. Study parameters-OAA/S scores and characteristics of sensory and motor blockade.

\begin{tabular}{|c|c|c|c|}
\hline & Group D $(\mathrm{n}=18)$ & Group M $(n=18)$ & $P$ value \\
\hline Time taken to achieve OAA/S 3 (min) & $21.3 \pm 8.8$ & $17.2 \pm 9.3$ & 0.27 \\
\hline $\begin{array}{l}\text { Maximum upper level of sensory } \\
\text { blockade (thoracic segments) }\end{array}$ & $5.3 \pm 1.3$ & $4.1 \pm 1.5$ & 0.03 \\
\hline $\begin{array}{l}\text { Time to the maximum upper } \\
\text { level of sensory blockade ( } \mathrm{min} \text { ) }\end{array}$ & $14.6 \pm 3.6$ & $13.4 \pm 3.9$ & 0.38 \\
\hline $\begin{array}{l}\text { Time for the two-segment regression } \\
\text { of sensory blockade (min) }\end{array}$ & $91.3 \pm 29.5$ & $94.4 \pm 29.9$ & 0.82 \\
\hline $\begin{array}{l}\text { Time for regression to the L2 level } \\
\text { of sensory blockade ( } \mathrm{min})\end{array}$ & $234.6 \pm 78.1$ & $172.4 \pm 41.5$ & 0.008 \\
\hline Time for motor blockade to Bromage 1 (min) & $3.7 \pm 0.9$ & $3.8 \pm 1.6$ & 0.95 \\
\hline $\begin{array}{l}\text { Time for the regression of motor } \\
\text { blockade to Bromage } 1 \text { (min) }\end{array}$ & $232.2 \pm 79.3$ & $176.5 \pm 48.8$ & 0.02 \\
\hline
\end{tabular}

Values are expressed as the mean \pm SD. OAA/S = Observer's Assessment of Alertness/Sedation scale.

motor blockade of modified Bromage score 1 between the two groups; however, the time for the regression of motor blockade to modified Bromage score 1 was significantly longer in group $\mathrm{D}$ than in group $\mathrm{M}(P=0.02)$. Ephedrine and/or atropine were used for hypotension and/or bradycardia in ten patients in group D (56\%) and five in group M $(28 \%)(P=0.11)$; however, significant hemodynamic changes caused by the study drugs were not observed in any patients. Furthermore, appreciable respiratory depression was not detected in any patients.

\section{Discussion}

The present results demonstrated that the intravenous administration of a loading dose of dexmedetomidine followed by continuous infusion at a maintenance dose, for sedation during spinal anesthesia, prolonged the duration of both sensory and motor blockade induced by spinal anesthesia over that with midazo- 
lam. Furthermore, dexmedetomidine did not alter the time required to reach the maximum upper level of sensory blockade. In the present study, patients who requested sedation during surgery were selected, and, thus, patients treated with physiological saline solution as a placebo were not included. Nevertheless, Patel $\mathrm{VH}$, et al. and Rekhi BK, et al. also reported that the continuous intravenous infusion of dexmedetomidine following an initial loading dose significantly prolonged the duration of sensory and motor blockade induced by spinal anesthesia over that with midazolam [9] [10]. In addition, in the present study, the time taken to achieve OAA/S score 3 was similar in the two groups, and the setting of the dosages of sedatives used were appropriate. Intravenous midazolam and dexmedetomidine are commonly used during regional anesthesia. Therefore, care is needed when using continuous intravenous dexmedetomidine, but not midazolam, for sedation during spinal anesthesia because the duration of spinal anesthesia will be prolonged.

In the present study, the maximum upper level of sensory blockade was lower in group D than in group M. Few studies have investigated the effects of continuous intravenous dexmedetomidine on the maximum upper level of sensory blockade. Dinesh CN, et al. reported that continuous intravenous dexmedetomidine at $1 \mu \mathrm{g} / \mathrm{kg}$ over 10 mins followed by a maintenance infusion of $0.5 \mu \mathrm{g} / \mathrm{kg} / \mathrm{h}$ increased the maximal level of sensory blockade over that with physiological saline [11]. In contrast, although other studies employed the same or a similar infusion protocol to that described by Dinesh $\mathrm{CN}$ et al., no significant differences were noted in the maximal level of sensory blockade between continuous intravenous dexmedetomidine and the control group [8] [9] [10] [12] [13]. A previous meta-analysis by Abdallah $\mathrm{FW}$, et al. concluded that intravenous dexmedetomidine did not increase the maximal level of sensory blockade [14]. However, the addition of epinephrine, an $\alpha$-adrenoreceptor agonist, to a bupivacaine/opioid mixture significantly lowered the maximum upper level of sensory blockade [15]. Dexmedetomidine, which is also an $\alpha$-adrenoreceptor agonist, may exert similar effects. Two different single doses of dexmedetomidine $(0.5$ $\mu \mathrm{g} / \mathrm{kg}$ and $1 \mu \mathrm{g} / \mathrm{kg}$ over $10 \mathrm{mins})$ resulted in a slightly lower level of sensory blockade in the dexmedetomidine group than in the saline group [16]. We were not able to elucidate the mechanisms responsible for this result in the present study; however, we do not consider the clinical meaning of the result to be significant because the difference in the maximum upper level of sensory blockade is only one dermatome.

Our results showed that the time for two-segment regression was similar in the two groups; however, a significant difference was observed in the time for regression to the L2 level of sensory blockade between the two groups. These results suggest that the speed of the regression of sensory blockade in group D was slower (non-linear regression of sensory blockade) after two-segment regression than in group M. In contrast, previous studies indicated that continuous intravenous dexmedetomidine significantly prolonged the time for the two-segment 
regression of sensory blockade [8] [10] [11] [17]. Furthermore, single-dose intravenous dexmedetomidine before or after spinal anesthesia also increased the time for the two-segment regression of sensory blockade [5] [18]. The difference between the results of the present study and these findings may be attributed to the different administration protocols of dexmedetomidine, namely, the difference in blood concentrations. Therefore, we attempted to simulate plasma concentrations of dexmedetomidine in our and some previous studies that described the mean age, body weight, and height of patients [5] [8] [10] using AnestAssist $^{\mathrm{TM}}$ PK/PDversion 1.9 (Palma Healthcare Systems LLC), an iPhone/iPad application for understanding and visualizing the pharmacokinetics, pharmacodynamics, and interactions of commonly used anesthetic drugs. The results obtained are shown in Figure 1. The predicted peak plasma concentration of dexmedetomidine in the first 15 minutes in our infusion protocol was lower than

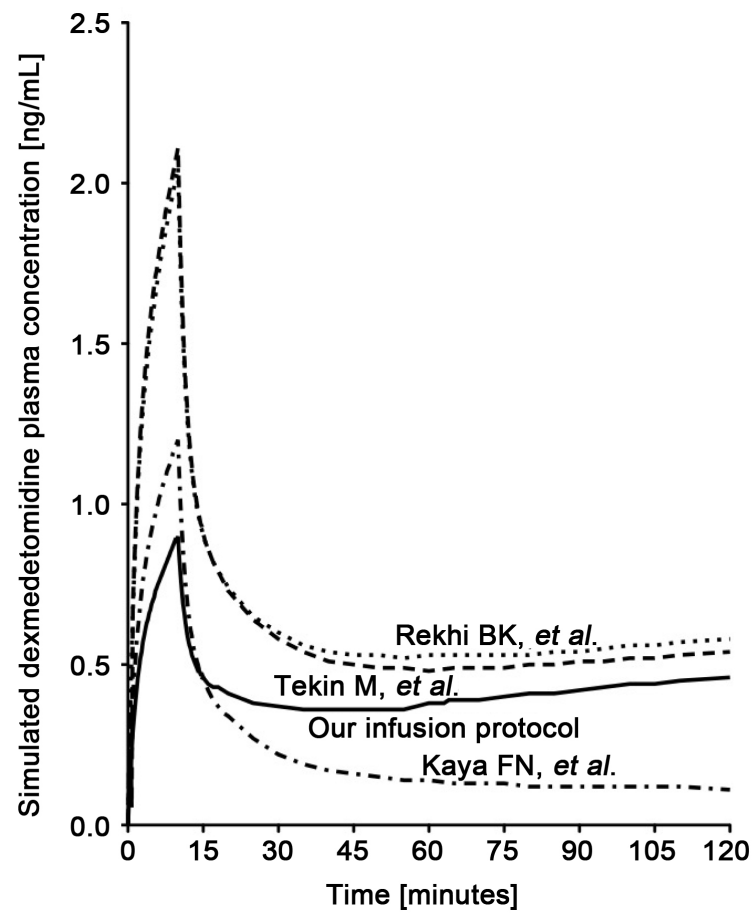

Figure 1. Simulated dexmedetomidine plasma concentration. The plasma dexmedetomidine concentrations of four intravenous administration protocols were simulated using Anest Assist ${ }^{\mathrm{TM}}$ PK/PD software: our infusion protocol (continuous line, continuous infusion of $0.5 \mu \mathrm{g} / \mathrm{kg} / \mathrm{h}$ followed by an initial loading dose of $0.5 \mu \mathrm{g} / \mathrm{kg}$ over $10 \mathrm{mins}$ ), Rekhi BK, et al. (dotted line, continuous infusion of $0.5 \mu \mathrm{g} / \mathrm{kg} / \mathrm{h}$ followed by an initial loading dose of $1 \mu \mathrm{g} / \mathrm{kg}$ over $10 \mathrm{mins}$ ), Tekin $\mathrm{M}$, et al. (dashed line, continuous infusion of $0.4 \mu \mathrm{g} / \mathrm{kg} / \mathrm{h}$ followed by an initial loading dose of $1 \mu \mathrm{g} / \mathrm{kg}$ over $10 \mathrm{mins}$ ), and Kaya FN, et al. (long dashed short dashed line, single dose of $0.5 \mu \mathrm{g} / \mathrm{kg}$ over $10 \mathrm{mins})$. The mean age, height, and body weight of patients administered dexmedetomidine in each study were used in the simulation as parameters. 
that in the other three investigators' protocols. Therefore, a high plasma concentration of dexmedetomidine in the early phase may mediate the prolongation of the two-segment sensory regression time. Moreover, the predicted plasma concentration from 15 minutes onward was higher than that in the study by Kaya FN et al. [5], and gradually became similar to those in the other two studies [8] [10]. This change in the predicted plasma concentration may have led to the result obtained for the regression time to the $\mathrm{L} 2$ level of sensory blockade in the present study. The initial loading dose of dexmedetomidine was suggested to be $6 \mu \mathrm{g} / \mathrm{kg} / \mathrm{h}$ for 10 minutes (equal to $1 \mu \mathrm{g} / \mathrm{kg}$ over 10 minutes). However, in our pilot study, excessive sedation occurred after the suggested initial loading dose in some patients, and, thus, it was set to $3 \mu \mathrm{g} / \mathrm{kg} / \mathrm{h}$ for 10 minutes (equal to 0.5 $\mu \mathrm{g} / \mathrm{kg}$ over 10 minutes). Therefore, if dexmedetomidinedose-dependently prolongs the duration of spinal anesthesia, the suggested initial loading dose of 6 $\mu \mathrm{g} / \mathrm{kg} / \mathrm{h}$ for 10 minutes may prolong the time for the two-segment regression of sensory blockade, similar to the simulation of the two other continuous infusion protocols. However, the administration of single-dose intravenous dexmedetomidine before undergoing spinal anesthesia did not appear to have a dose-dependent prolongation effect on sensory blockade [16]. Further studies are needed in order to investigate the contribution of the dexmedetomidine dose and its prolongation effect on the duration of spinal anesthesia.

In the present study, continuous intravenous dexmedetomidine significantly prolonged the duration of motor blockade over that with midazolam. The similar prolongation of the duration of motor blockade was observed in studies on the continuous infusion of dexmedetomidine following an initial loading dose [8] [10] [11] [13] [19]. In contrast, single-dose intravenous administration did not extend the duration of motor blockade in three previous studies [5] [16] [20]. Furthermore, continuous infusion without an initial loading dose and the BIS-targeted continuous infusion of dexmedetomidine did not prolong the duration of the sensory or motor blockade induced by spinal anesthesia [21] [22]. The mechanisms underlying the prolongation of motor and sensory blockade induced by the administration of dexmedetomidine remain unclear, and the different infusion protocols for the administration of dexmedetomidine may affect the duration of motor blockade. On the other hand, we consider the prolongation of motor blockade to not necessarily be desirable due to the extension of the time until early ambulation and discharge, whereas the extension of the duration of analgesia is clinically favorable.

In patients who received continuous intravenous dexmedetomidine following an initial loading dose, bradycardia was a more common hemodynamic adverse effect than hypotension [14]. Previous studies by Tekin M, et al. and Rekhi BK, et al. showed that bradycardia occurred in the first 15 - 20 mins after the initiation of administration [8] [10]. Therefore, the rapid increase observed in the plasma concentration of dexmedetomidine induced by the initial loading dose (Figure 1) appears to have caused bradycardia in the initial phase of administra- 
tion [23]. In the present study, no significant differences were observed in the percentage of patients administered the cardiovasoactive drugs between the two groups, and the loading dose set to $3 \mu \mathrm{g} / \mathrm{kg} / \mathrm{h}$ in our protocol may have influenced this result. Nevertheless, previous studies indicated that bradycardia was transient and easily reversed with intravenous atropine [10] [11] [12] [20].

There are several limitations in the present study. The sample size was small, and thus, a larger sample size needs to be examined. Furthermore, a physiological saline group was not included in the present study. Talakoub $\mathrm{R}$, et al. reported that $0.03 \mathrm{mg} / \mathrm{kg}$ of intravenous midazolam significantly extended the duration of the motor blockade of lidocaine spinal anesthesia over that with saline [24]. Therefore, the addition of a saline group as a placebo may be preferable for observing the effects of dexmedetomidine itself on the duration of spinal anesthesia.

\section{Conclusion}

Continuous intravenous dexmedetomidine to provide sedation during surgery significantly prolonged the duration of sensory and motor blockade induced by bupivacaine spinal anesthesia and lowered the maximal level of sensory blockade over that with midazolam.

\section{Conflicts of Interest}

The authors declare that they have no conflicts of interest in relation to this study.

\section{References}

[1] Wilson, E., David, A., MacKenzie, N. and Grant, I.S. (1990) Sedation during Spinal Anaesthesia: Comparison of Propofol and Midazolam. British Journal of Anaesthesia, 64, 48-52. https://doi.org/10.1093/bja/64.1.48

[2] Arain, S.R. and Ebert, T.J. (2002) The Efficacy, Side Effects, and Recovery Characteristics of Dexmedetomidine versus Propofol When Used for Intraoperative Sedation. Anesthesia \& Analgesia, 95, 461-466.

[3] Candiotti, K.A., Bergese, S.D., Bokesch, P.M., Feldman, M.A., Wisemandle, W. and Bekker, A.Y. (2010) Monitored Anesthesia Care with Dexmedetomidine: A Prospective, Randomized, Double-Blind, Multicenter Trial. Anesthesia \& Analgesia, 110, 47-56. https://doi.org/10.1213/ane.0b013e3181ae0856

[4] Kanazi, G.E., Aouad, M.T., Jabbour-Khoury, S.I., Al Jazzar, M.D., Alameddine, M.M., Al-Yaman, R., Bulbul, M. and Baraka, A.S. (2006) Effect of Low-Dose Dexmedetomidine or Clonidine on the Characteristics of Bupivacaine Spinal Block. Acta Anaesthesiologica Scandinavia, 50, 222-227. https://doi.org/10.1111/j.1399-6576.2006.00919.x

[5] Kaya, F.N., Yavascaoglu, B., Turker, G., Yildirim, A., Gurbet, A., Mogol, E.B. and Ozcan, B. (2010) Intravenous Dexmedetomidine, But Not Midazolam, Prolongs Bupivacaine Spinal Anesthesia. Canadian Journal of Anesthesia, 57, 39-45. https://doi.org/10.1007/s12630-009-9231-6

[6] Chernik, D.A., Gillings, D., Laine, H., Hendler, J., Silver, J.M., Davidson, A.B., 
Schwan, E.M. and Siegel, J.L. (1990) Validity and Reliability of the Observer's Assessment of Awareness/Sedation Scale: Study with Intravenous Midazolam. Journal of Clinical Psychopharmacology, 10, 244-251.

[7] Bromage, P.R. (1965) A Comparison of the Hydrochloride and Carbon Dioxide Salts of Lidocaine and Prilocaine in Epidural Analgesia. Acta Anaesthesiologica Scandinavia, 16, 55-69. https://doi.org/10.1111/j.1399-6576.1965.tb00523.x

[8] Tekin, M., Kati, I., Tomak, Y. and Kisli, E. (2007) Effect of Dexmedetomidine IV on the Duration of Spinal Anesthesia with Prilocaine: A Double-Blind, Prospective Study in Adult Surgical Patients. Current Therapeutic Research, Clinical and Experimental, 68, 313-324. https://doi.org/10.1016/j.curtheres.2007.10.006

[9] Patel, V.H. and Patel, H.R. (2016) A Comparison between Dexmedetomidine and Midazolam Infusion on Characteristic of Spinal Anesthesia. International Journal of Medical Science and Public Health, 5, 906-910.

https://doi.org/10.5455/ijmsph.2016.21072015313

[10] Rekhi, B.K., Kaur, T., Arora, D. and Dugg, P. (2017) Comparison of Intravenous Dexmedetomidine with Midazolam in Prolonging Spinal Anaesthesia with Ropivacaine. Journal of Clinical and Diagnostic Research, 11, UC01-UC04.

[11] Dinesh, C.N., Sai Tej, N.A., Yatish, B., Pujari, V.S., Mohan Kumar, R.M. and Mohan, C.V. (2014) Effects of Intravenous Dexmedetomidine on Hyperbaric Bupivacaine Spinal Anesthesia: A Randomized Study. Saudi Journal of Anaesthesia, 8, 202-208. https://doi.org/10.4103/1658-354X.130719

[12] Elcicek, K., Tekin, M. and Kati, I. (2010) The Effects of Intravenous Dexmedetomidine on Spinal Hyperbaric Ropivacaine Anesthesia. Journal of Anesthesia, 24, 544-548. https://doi.org/10.1007/s00540-010-0939-9

[13] Agrawal, A., Agrawal, S. and Payal, Y.S. (2016) Comparison of Block Characteristics of Spinal Anesthesia Following Intravenous Dexmedetomidine and Clonidine. Journal of Anaesthesiology, Clinical Pharmacology, 32, 339-343. https://doi.org/10.4103/0970-9185.188830

[14] Abdallah, F.W., Abrishami, A. and Brull, R. (2013) The Facilitatory Effects of Intravenous Dexmedetomidine on the Duration of Spinal Anesthesia: A Systematic Review and Meta-Analysis. Anesthesia \& Analgesia, 117, 271-278. https://doi.org/10.1213/ANE.0b013e318290c566

[15] Gautier, P.E., Debry, F., Fanard, L., Van Steenberge, A. and Hody, J.L. (1997) Ambulatory Combined Spinal-Epidural Analgesia for Labor. Influence of Epinephrine on Bupivacaine-Sufentanil Combination. Regional Anesthesia, 22, 143-149. https://doi.org/10.1016/S1098-7339(06)80033-7

[16] Lee, M.H., Ko, J.H., Kim, E.M., Cheung, M.H., Choi, Y.R. and Choi, E.M. (2014) The Effects of Intravenous Dexmedetomidine on Spinal Anesthesia: Comparison of Different Dose of Dexmedetomidine. Korean Journal of Anesthesiology, 67, 252-257. https://doi.org/10.4097/kjae.2014.67.4.252

[17] Santpur, M.U., Kahalekar, G.M., Saraf, N. and Losari, A. (2016) Effect of Intravenous Dexmedetomidine on Spinal Anaesthesia with 0.5\% Hyperbaric Bupivacaine in Lower Abdominal Surgeries: A Prospective Randomized Control Study. Anesthesia, Essays and Researches, 10, 497-501. https://doi.org/10.4103/0259-1162.179319

[18] Jung, S.H., Lee, S.K., Lim, K.J., Park, E.Y., Kang, M.H., Lee, J.M., Lee, J.J., Hwang, S.M. and Hong, S.J. (2013) The Effects of Single-Dose Intravenous Dexmedetomidine on Hyperbaric Bupivacaine Spinal Anesthesia. Journal of Anesthesia, 27, 380-384. https://doi.org/10.1007/s00540-012-1541-0

[19] Al-Mustafa, M.M., Badran, I.Z., Abu-Ali, H.M., Al-Barazangi, B.A., Massad, I.M. 
and Al-Ghanem, S.M. (2009) Intravenous Dexmedetomidine Prolongs Bupivacaine Spinal Analgesia. Middle East Journal of Anaesthesiology, 20, 225-231.

[20] Gupta, K., Tiwari, V., Gupta, P.K., Pandey, M.N., Agarwal, S. and Arora, A. (2014) Prolongation of Subarachnoid Block by Intravenous Dexmedetomidine for Subumbilical Surgical Procedures: A Prospective Control Study. Anesthesia, Essays and Researches, 8, 175-178. https://doi.org/10.4103/0259-1162.134494

[21] Zhang, H., Li, M., Zhang, S.-Y., Fu, M. and Zhang, S.-Y. (2016) Intravenous Dexmedetomidine Promotes Spinal Bupivacaine Anesthesia and Postoperative Analgesia in Lower Limb Surgery: A Double-Blind, Randomized Clinical CONSORT Study. Medicine, 95, e2880. https://doi.org/10.1097/MD.0000000000002880

[22] Magalhães, E., Ladeira, L.C., Govêia, C.S. and Espíndola, B.V. (2006) Intravenous Dexmedetomidine for Sedation Does Not Interfere with Sensory and Motor Block Duration during Spinal Anesthesia. Revista Brasileira de Anestesiologia, 56, 1-7. https://doi.org/10.1590/S0034-70942006000100001

[23] Ebert, T.J., Hall, J.E., Barney, J.A., Uhrich, T.D. and Colinco, M.D. (2000) The Effects of Increasing Plasma Concentrations of Dexmedetomidine in Humans. Anesthesiology, 93, 382-394. https://doi.org/10.1097/00000542-200008000-00016

[24] Talakoub, R., Rezvani, M., Alikhani, A., Golparvar, M., Jabalameli, M. and Amini, Z. (2015) The Effect of Intravenous Midazolam on Duration of Spinal Anesthesia. Shiraz e-Medical Journal, 16, e21586. https://doi.org/10.17795/semj21586 